\title{
Podridão por Fusicoccum em mangas submetidas a baixas doses de radiação gama
}

\author{
Alice Maria Gonçalves Santos(1), Sônia Maria Alves de Oliveira(1), Josenilda Maria da Silva(2) ${ }^{(2)}$ Daniel Terao ${ }^{(3)}$
}

(1)Universidade Federal Rural de Pernambuco, Av. Dom Manuel de Medeiros s/n, Dois Irmãos, CEP 52171-900 Recife, PE. E-mail: alicemgsantos@yahoo.com.br, s.oliveira@depa.ufrpe.br ${ }^{(2)}$ Centro Regional de Ciências Nucleares, Av. Prof. Luiz Freire, 200, Cidade Universitária, CEP 50704-540 Recife, PE. E-mail: jmnilda@cnen.gov.br ${ }^{(3)}$ Embrapa Semiárido, BR 428, Km 152, CEP 56302-970 Petrolina, PE. E-mail: daniel.terao@cpatsa.embrapa.br

\begin{abstract}
Resumo - O objetivo deste trabalho foi avaliar o efeito da radiação gama em doses baixas no controle pós-colheita da podridão por Fusicoccum em manga 'Tommy Atkins', bem como avaliar o efeito desse método sobre as características físico-químicas da fruta. Frutos aparentemente livres de doenças no estádio de maturação 1,5 foram inoculados com $10 \mu \mathrm{L}$ de suspensão de Fusicoccum parvum a $10^{6}$ conídios $\mathrm{mL}^{-1}$. Após a inoculação, os frutos foram irradiados com as doses de $0,24,0,35$ e $0,45 \mathrm{kGy}$ e armazenados a $13^{\circ} \mathrm{C}$, durante 15 dias, seguidos de mais seis dias em temperatura ambiente, a $25^{\circ} \mathrm{C}$. A dose mais alta de radiação gama foi eficiente em retardar o desenvolvimento da doença em razão do atraso causado na maturação das frutas. Não houve efeito significativo da radiação sobre as características físico-químicas das frutas. Os frutos mantiveram características ideais para comercialização, mesmo após o armazenamento refrigerado, com a presença de filme plástico, por 15 dias.

Termos para indexação: Fusicoccum parvum, Mangifera indica, características físico-químicas, manejo físico, tempo de prateleira.
\end{abstract}

\section{Fusicoccum rot in mangoes submitted to low doses of gamma irradiation}

Abstract - This study aimed to evaluate the effect of gamma irradiation in low doses on the postharvest control of 'Tommy Atkins' mango rot caused by Fusicoccum, and to evaluate the effect of this method on the physicochemical characteristics of the fruit. Fruits in ripening stage 1,5 and apparently free of disease were inoculated with $10 \mu \mathrm{L}$ of a Fusicoccum parvum suspension at $10^{6}$ conidia $\mathrm{mL}^{-1}$. They were gamma irradiated with the doses $0.24,0.35$ and $0.45 \mathrm{kGy}$, and stored under $13^{\circ} \mathrm{C}$ for 15 days, followed by a further six days at room temperature, $25^{\circ} \mathrm{C}$. The higher dose of gamma radiation was effective in delaying the disease development due to fruit delayed maturation. No significant effect of radiation was observed on fruit physicochemical characteristics. Fruit maintained ideal commercialization features even after cold storage, in the presence of plastic film, for 15 days.

Index terms: Fusicoccum parvum, Mangifera indica, physical-chemistry characteristics, physical control, shelf life.

\section{Introdução}

A manga (Mangifera indica L.) é uma fruta tipicamente tropical, que apresenta grande potencial para o mercado de exportação. Apesar de existirem fatores limitantes ao comércio da manga, o Brasil tem apresentado taxa média de crescimento anual de 30\% nas exportações, acima da média mundial de 14\% (Araújo, 2007).

No entanto, os três principais concorrentes brasileiros nesse mercado, México, Índia e Tailândia, também têm apresentado crescimentos significativos em suas exportações. Dessa forma, o País permanece como o quarto exportador mundial de mangas, com aproximadamente $12 \%$ do mercado (Food and
Agriculture Organization of the United Nations, 2009). O sucesso da participação brasileira no mercado externo está associado ao alto nível tecnológico adotado pelos produtores nacionais, que permite o atendimento de padrões internacionais de qualidade.

Segundo Sousa et al. (2002), a necessidade de se ampliar o conhecimento sobre técnicas de conservação pós-colheita de frutas e de seus efeitos na qualidade da manga produzida no Brasil é muito importante para as exportações. De acordo com Hiluey et al. (2005), as tecnologias pós-colheita existentes e aplicáveis à conservação da manga têm o objetivo de prevenir a ação de doenças e pragas, assim como lesões durante transporte e embalagem. 
O emprego da irradiação de alimentos no Brasil é muito promissor, com bons resultados na redução das perdas pós-colheita (Lima et al., 2001). O processo de irradiação foi descrito por O'Beirne (1989) como o uso de raios gama em alimentos, sem que haja risco de contaminação radioativa. A eficiência do uso da radiação gama como tecnologia de conservação de alimentos está ligada basicamente a três fatores: tipo de alimento a ser irradiado, dose a ser aplicada e tempo de exposição do alimento à fonte irradiadora (Vieites, 1998). A radiação para a conservação de alimentos, isoladamente, não é eficaz na redução de perdas, pois, ao contrário dos métodos químicos convencionais, ela não possui efeito residual, e a possibilidade de reinfestação por microrganismos existe (Neves et al., 2002). Além disso, o uso dessa técnica apresenta alguns inconvenientes, como a possibilidade de ocorrência de esmorecimento e amaciamento dos frutos, aparecimento de depressões superficiais, amadurecimento anormal e perda de aroma e sabor dos produtos (Nagajara, 2007), a depender da dose aplicada e das condições ambientais durante e após a irradiação.

A aplicação de radiação ionizante pode alterar componentes estruturais de determinados frutos e proporcionar-lhes melhor aspecto, com aumento da firmeza. Baixas doses de radiação resultam na hidrólise de certos componentes, que podem aumentar a vida útil do produto e a conversão de amidos em açúcares (Lima et al., 2001).

O objetivo deste trabalho foi avaliar o efeito da radiação gama em doses baixas no controle pós-colheita da podridão por Fusicoccum em manga 'Tommy Atkins' e sobre as características físico-químicas da fruta.

\section{Material e Métodos}

O experimento foi conduzido no Laboratório de Patologia Pós-Colheita da Universidade Federal Rural de Pernambuco (UFRPE), no Laboratório GamaLab do Departamento de Energia Nuclear da Universidade Federal de Pernambuco e no Laboratório de Pós-Colheita de Frutos do Centro Regional de Ciências Nucleares.

O fungo fitopatogênico utilizado neste trabalho foi cedido pela Embrapa Semiárido. O isolado obtido foi cultivado em meio batata-dextrose-ágar (BDA) e inoculado em mangas sadias para reproduzir os sintomas.
Para a avaliação do efeito da radiação gama sobre o desenvolvimento da podridão por Fusicoccum, foram utilizadas mangas da cultivar Tommy Atkins colhidas no estádio de maturação 1,5 - frutas ainda firmes com coloração verde-clara apresentando partes avermelhadas - em pomar comercial da Fazenda CopaFruit, situada em Petrolina, PE. Após a colheita, as frutas foram transportadas até o laboratório de Patologia Pós-Colheita da UFRPE, onde foram selecionadas, lavadas e secas ao ar sob temperatura de $26 \pm 2^{\circ} \mathrm{C}$ e umidade relativa (UR) de $70 \pm 5 \%$. Em seguida, as frutas foram feridas com uso de furador, com oito agulhas de $2 \mathrm{~mm}$, na região próxima ao pedúnculo. Sobre os frutos, foram depositados $10 \mu \mathrm{L}$ de uma suspensão de conídios de Fusicoccum parvum na concentração de $10^{6}$ conídios $\mathrm{mL}^{-1}$, com uso de um pipetador automático. As testemunhas foram feridas e inoculadas com $10 \mu \mathrm{L}$ de água destilada esterilizada (ADE).

As mangas foram dispostas aos pares, em bandejas de poliestireno expandido $(15 \mathrm{~cm} \times 10 \mathrm{~cm})$, com completo envolvimento em filme de plástico transparente de cloreto de polivinila (PVC esticável), para modificar o ambiente. Os conjuntos foram mantidos em ambiente laboratorial $\left(26 \pm 2^{\circ} \mathrm{C} ; 70 \pm 5 \%\right.$ UR $)$ durante $24 \mathrm{~h}$. Após esse período, as bandejas contendo as mangas receberam os tratamentos com as doses de radiação gama previamente determinadas: 0,$25 ; 0,35 ; 0,45 \mathrm{kGy}$, utilizando um radiador Gammacell 220Excel (MDS Nordion, Canadá), cuja taxa no momento da aplicação era 7,222 $\mathrm{kGy} \mathrm{h}^{-1}$, tendo o Cobalto ${ }^{60}$ como fonte de radiação. A testemunha relativa foi composta de frutas com inoculação do fitopatógeno e não irradiadas, e a testemunha absoluta não sofreu inoculação nem irradiação.

Após as aplicações das doses, as bandejas irradiadas e as não irradiadas foram acondicionadas em câmara fria a $13^{\circ} \mathrm{C}$, onde permaneceram por 15 dias. Em seguida foram mantidas em sala de incubação sem a presença do filme de plástico, sob temperatura de $26 \pm 2^{\circ} \mathrm{C}$ e $70 \%$ de umidade relativa, por um período de seis dias.

$\mathrm{O}$ experimento foi conduzido em delineamento inteiramente casualizado, com quatro tratamentos e quatro repetições, cada repetição com cinco frutas para as avaliações fitopatológicas e outras cinco para avaliação das características físico-químicas.

A avaliação da severidade da doença consistiu na medição do diâmetro da lesão com o auxílio de um paquímetro Vernier Caliper (Mitutoyo, Kawasaki, 
Japão), após a saída da câmara fria, e a cada dois dias, até a degeneração das frutas, sete dias após a saída. Os dados obtidos foram submetidos à análise de variância e de regressão, cujo modelo foi definido pelo coeficiente de determinação, utilizando-se o programa SAS (SAS Institute, 2000).

Para as análises físico-químicas, as frutas foram avaliadas em quatro épocas diferentes: na entrada da câmara (dia 1); 15 dias após, na saída da câmara (dia 15); dois dias após a saída da câmara (dia 17); e quatro dias após a saída da câmara (dia 19). As características avaliadas foram: firmeza da polpa, cor da polpa, potencial hidrogeniônico $(\mathrm{pH})$, sólidos solúveis totais (SST), ácidez titúlavel (AT), ácido ascórbico (Vitamina C) e índice de maturação (IM) determinado pela razão SST/AT.

A análise física de firmeza foi realizada após a saída da câmara fria, aos 15, 17 e 19 dias, pela determinação da resistência da polpa à penetração de penetrômetro do tipo Penetrometer Fruit Pressure test modelo FT 327 (0-13 Lbs.) (Wagner Instruments, Greenwich, Londres). Os resultados foram expressos em newton $(\mathrm{N})$.

A análise de cor da polpa, realizada em quatro épocas distintas, conforme avaliação química, foi avaliada com uso de um colorímetro Minolta CR-300, para obtenção dos valores de $\mathrm{L}^{*}, \mathrm{a}^{*} \mathrm{e} \mathrm{b}^{*}$, com três leituras por amostra, em partes distintas da polpa. Os valores de $\mathrm{L}^{*}$ variaram de 0 (branco) a 100 (preto) e representaram a luminosidade da polpa; os de a* indicam a cromaticidade que tende do verde $(-)$ ao vermelho $(+)$; e os de $b^{*}$ indicam a cromaticidade que varia do azul (-) até o amarelo $(+)$.

As características químicas foram determinadas após desintegração da polpa, em centrífuga doméstica. Trabalhou-se com três repetições para cada fruto. Na determinação de sólidos solúveis, foram utilizados $20 \mu \mathrm{L}$ do suco, depositados sobre o visor do refratômetro modelo $\mathrm{RCZ}\left(0-32^{\circ} \mathrm{Brix}\right)$ (Bel Equipamentos Analíticos Ltda., Piracicaba, São Paulo). Os resultados foram expressos em ${ }^{\circ}$ Brix. A acidez titulável foi determinada segundo a metodologia descrita por Ohlweider (1980). O pH foi verificado em $10 \mathrm{~g}$ da polpa triturada, com leitura direta em potenciômetro Quimis modelo Q-400 ${ }^{\mathrm{A}}$ (Quimis Aparelhos Científicos Ltda., Diadema, São Paulo). Para quantificar o teor de ácido ascórbico, seguiu-se a metodologia descrita por Carvalho et al. (1990).
Os dados obtidos foram submetidos à análise de variância e de regressão, cujo modelo foi definido pelo coeficiente de determinação, utilizando-se o programa SAS (SAS Institute, 2000). Quanto aos dados de firmeza, foi utilizado o teste de Tukey a 5\% de probabilidade.

\section{Resultados e Discussão}

A presença da cobertura de PVC durante o armazenamento das mangas em câmara fria não proporcionou o desenvolvimento de manchas nas cascas ou outras alterações nas frutas, diferentemente dos resultados encontrados por Pfaffenbach et al. (2003) que, ao trabalhar com filme de plástico e refrigeração, constatou a presença de manchas após o período de armazenamento. Sousa et al. (2000), com uso de refrigeração e do filme PVC, verificaram a possibilidade de aumento na vida de prateleira das frutas.

Na primeira avaliação dos efeitos da radiação sobre o desenvolvimento da podridão por Fusicoccum, realizada após a saída da câmara fria, observou-se que as frutas não apresentavam sintomas de podridão decorrente da inoculação com o patógeno. As frutas apresentavam boa aparência, com a coloração da casca uniforme e sem manchas em todos os tratamentos. A maturação das frutas por ocasião da saída da câmara fria esteve em torno do estádio 3 - frutas com áreas iguais de coloração verde e amarela - de acordo com escala utilizada por Assis (2004). Na segunda avaliação, realizada dois dias após a saída da câmara, foi verificada a incidência da doença em todos os tratamentos, com diferenças significativas na severidade. Os tratamentos com as doses de radiação gama 0,25 e 0,35 kGy não apresentaram comportamento diferente da testemunha não irradiada (Figura 1). O desenvolvimento da lesão nas mangas tratadas com a dose de $0,45 \mathrm{kGy}$, no entanto, foi menor.

Existem trabalhos que comprovam a eficiência da radiação gama em reduzir a incidência de doenças em frutas como manga, cultivar Tommy Atkins (Zuleta, 1989), abacaxi (Urbain, 1986), uva (Thomas et al.,1985), mamão (Cia et al., 2007) e nectarina (Neves et al., 2002). De acordo com Nagaraja (2007), a irradiação de frutas e hortaliças pós-colheita tem como principal interesse a redução nos danos causados por doenças, e atua como fungicida. Contudo, é também 
utilizada como método de conservação, por prolongar $\mathrm{o}$ armazenamento pelo retardo do amadurecimento e do brotamento de alguns produtos vegetais, em razão de pequenas alterações fisiológicas nos frutos.

No que se refere às características físico-químicas das frutas, a firmeza da polpa permanece praticamente constante durante os estádios iniciais de amadurecimento da manga, e decresce a partir da maturidade fisiológica (Subedi et al., 2007). A aplicação da radiação gama influenciou os valores de firmeza nas frutas submetidas a doses de radiação em relação à testemunha (Tabela 1). No entanto, na ultima avaliação, apenas as mangas irradiadas com a maior dose apresentaram maior firmeza

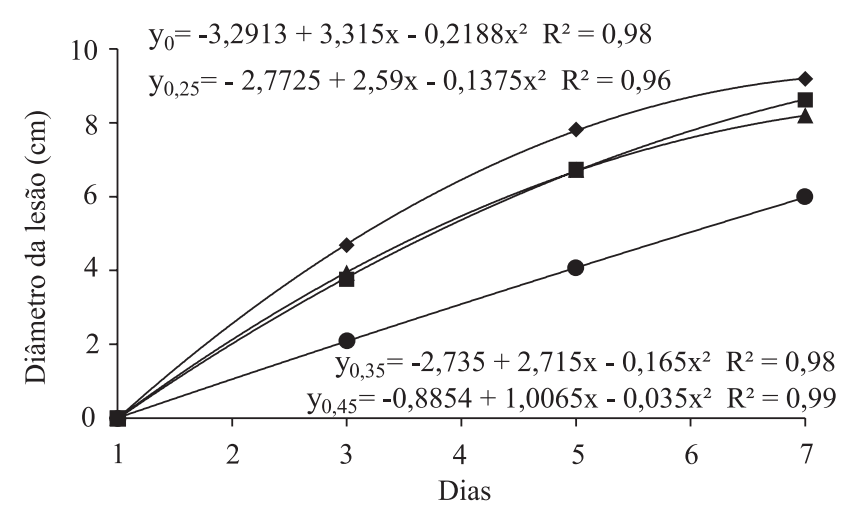

Dose 0

Dose 0,25

А Dose 0,35

Figura 1. Desenvolvimento da podridão peduncular de mangas 'Tommy Atkins' submetidas à inoculação de Fusicoccum parvum e irradiadas nas doses de 0;0,25; 0,35 e $0,45 \mathrm{kGy}$ de raios gama, após a saída das frutas da câmara fria ( 15 dias em armazenamento refrigerado a $13^{\circ} \mathrm{C}$, com cobertura de filme PVC). Após a saída, as frutas foram armazenadas a $26^{\circ} \mathrm{C}$ e $90 \%$ de UR, sem a cobertura de filme PVC.

Tabela 1. Firmeza da polpa (N) de mangas 'Tommy Atkins' submetidas à inoculação de Fusicoccum parvum e irradiadas com diferentes doses de raios gama, após armazenamento refrigerado a $13^{\circ} \mathrm{C}$ por 15 dias, e após armazenamento em condições ambiente ${ }^{(1)}$ por mais quatro dias ${ }^{(2)}$.

\begin{tabular}{lrrrr}
\hline Dias & \multicolumn{4}{c}{ Doses de radiação gama (kGy) } \\
\cline { 2 - 5 } & 0 & \multicolumn{1}{c}{0,25} & 0,35 & 0,45 \\
\hline 15 & $14,71 \mathrm{Ba}$ & $20,39 \mathrm{Aa}$ & $25,70 \mathrm{Aa}$ & $26,48 \mathrm{Aa}$ \\
17 & $10,59 \mathrm{Cb}$ & $14,90 \mathrm{Bb}$ & $20,21 \mathrm{Aa}$ & $23,34 \mathrm{Aa}$ \\
19 & $7,84 \mathrm{Bc}$ & $8,63 \mathrm{Bc}$ & $10,00 \mathrm{Bb}$ & $15,29 \mathrm{Ab}$ \\
\hline CV $(\%)$ & \multicolumn{4}{c}{8,72} \\
\hline
\end{tabular}

${ }^{(1)}$ Temperatura $26^{\circ} \mathrm{C}$ e umidade relativa de $90 \%$, sem a cobertura do filme PVC. (2)Médias seguidas de letras iguais, maiúsculas nas linhas e minúsculas nas colunas, não diferem entre si pelo teste de Tukey a $5 \%$ de probabilidade. do que a testemunha. Dessa forma, observa-se que a radiação foi eficiente em promover a manutenção da firmeza das frutas, resultado semelhante aos de Calore \& Vieites (2003) com pêssego.

As análises estatísticas comprovaram que não ocorreu interferência da radiação gama sobre a coloração da polpa das mangas e sim diferenças devido ao amadurecimento das frutas, constatadas em relação aos dias de avaliação. Para a variável $\mathrm{L}^{*}$, o comportamento da luminosidade foi o de decréscimo ao longo dos dias de avaliação (Figura 2). Para os valores de $\mathrm{a}^{*}$, observouse comportamento quadrático, com aumento dos pigmentos referentes à coloração vermelha nas polpas ao final da avaliação, que consiste no escurecimento das manchas à medida que as frutas amadurecem. Os valores de $b^{*}$ revelaram aumento da cor amarela
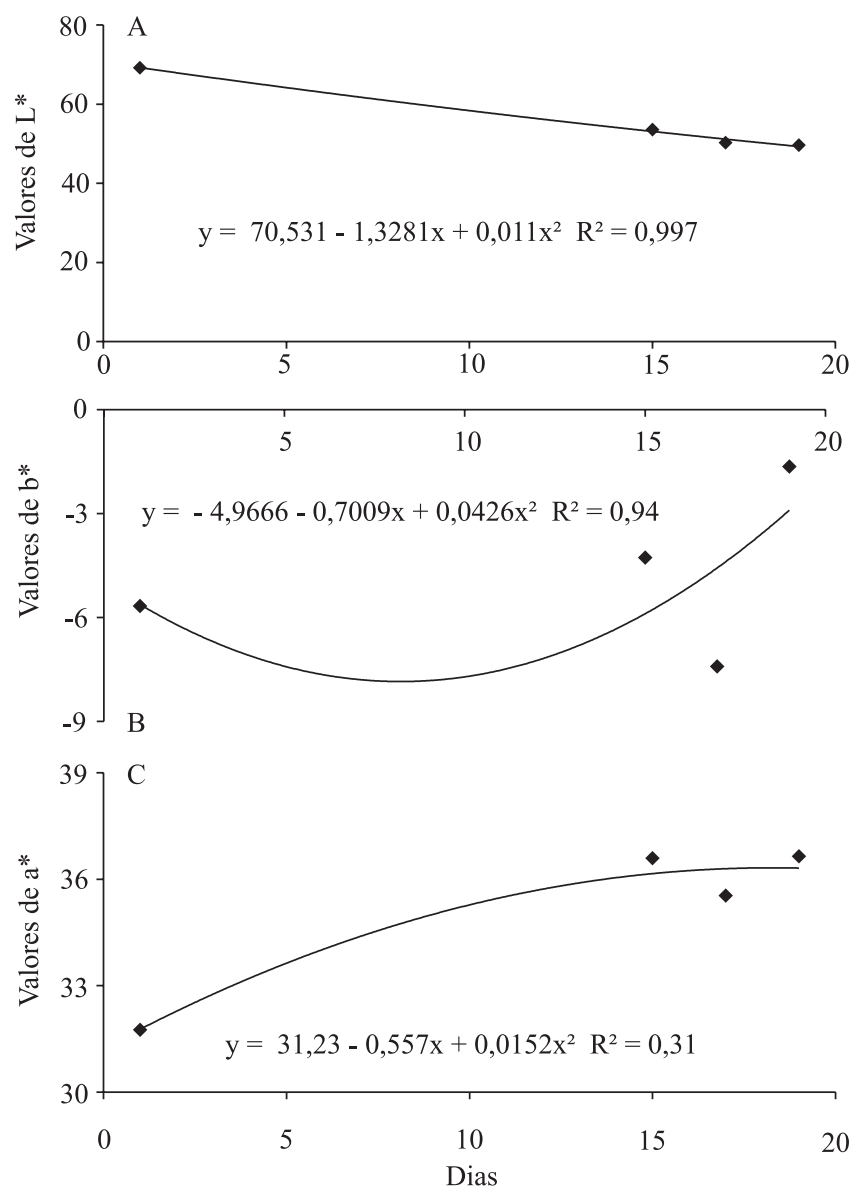

Figura 2. Efeito dos dias de armazenamento sobre a cor da polpa de mangas 'Tommy Atkins'. L*, valores de luminosidade que variam de 0 (preto) a 100 (branco); $a^{*}$, valores de cromaticidade vermelho-verde (+a, vermelho; -a, verde); $b^{*}$, valores de cromaticidade amarelo-azul (+b, amarelo; -b, azul). 
com a maturação. Sousa et al. (2002), ao estudar a qualidade da polpa de mangas 'Tommy Atkins', verificaram que a redução do parâmetro de cor está relacionada ao amadurecimento das frutas e pode ser alterada com o tipo de tratamento aplicado durante a pós-colheita. Quanto ao teor de ácido ascórbico presente nas frutas, observou-se interação entre as doses de radiação gama aplicadas e os dias de avaliação. De acordo com Chitarra \& Chitarra (2005), perdas substanciais de nutrientes podem ocorrer com o armazenamento, especialmente de vitamina C. Observou-se que a inclinação da reta que descreve a redução dos teores de ácido ascórbico nas frutas que não receberam irradiação foi maior do que nas que receberam (Figura 3). De acordo com os resultados, a irradiação promove uma leve redução nos teores iniciais de ácido ascórbico nos frutos, mas confere maior estabilidade desses valores ao longo do processo de maturação. Resultados semelhantes foram encontrados por Youssef et al. (2002), em trabalho
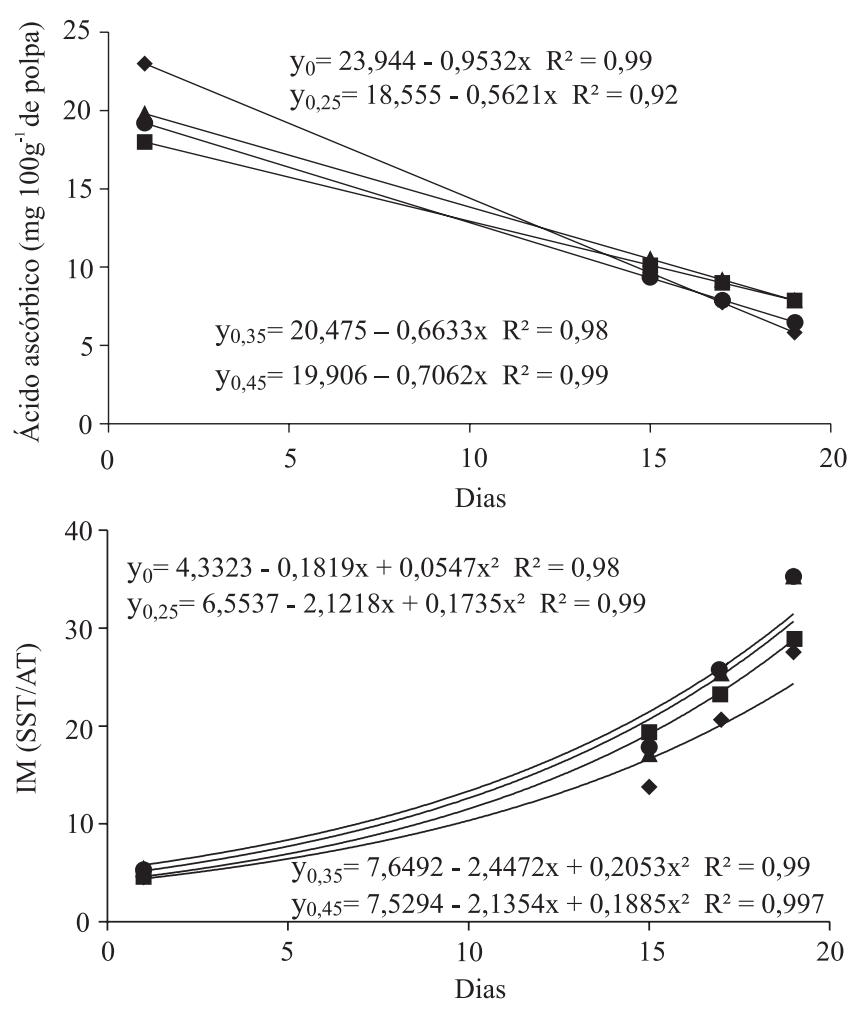

Dose 0

Dose 0,25

Dose 0,35

Dose 0,45

Figura 3. Interação entre os efeitos das doses de radiação gama (kGy) e dias de avaliação sobre os teores de ácido ascórbico e sobre o índice de maturação (IM) de mangas 'Tommy Atkins'. IM, índice de maturação; SST, sólidos solúveis totais; AT, acidez titulável. com radiação gama em mangas, em que doses entre 0,5 e 2,0 kGy aumentaram os valores de ácido ascórbico ao final da maturação em relação às frutas não tratadas.

O índice de maturação (razão SST/AT) também sofreu interação entre doses e dias de avaliação. A maior dose aplicada $(0,45 \mathrm{kGy})$ proporcionou aumento no índice de maturação ao final das avaliações (Figura 3). Xavier et al. (2009) afirmam que os valores da relação entre as duas variáveis envolvidas no índice de maturação são mais representativos que a medida isolada de açúcar e de acidez, pois essa razão dá uma boa idéia do equilíbrio entre esses dois componentes da qualidade dos frutos.

Os valores de sólidos solúveis, acidez titulável e pH não foram alterados pela aplicação das doses de radiação gama, e sim pelo amadurecimento das frutas (Figura 4). $\mathrm{O}$ aumento dos valores de SST indica o ponto de maturação fisiológica e, consequentemente, o ponto de
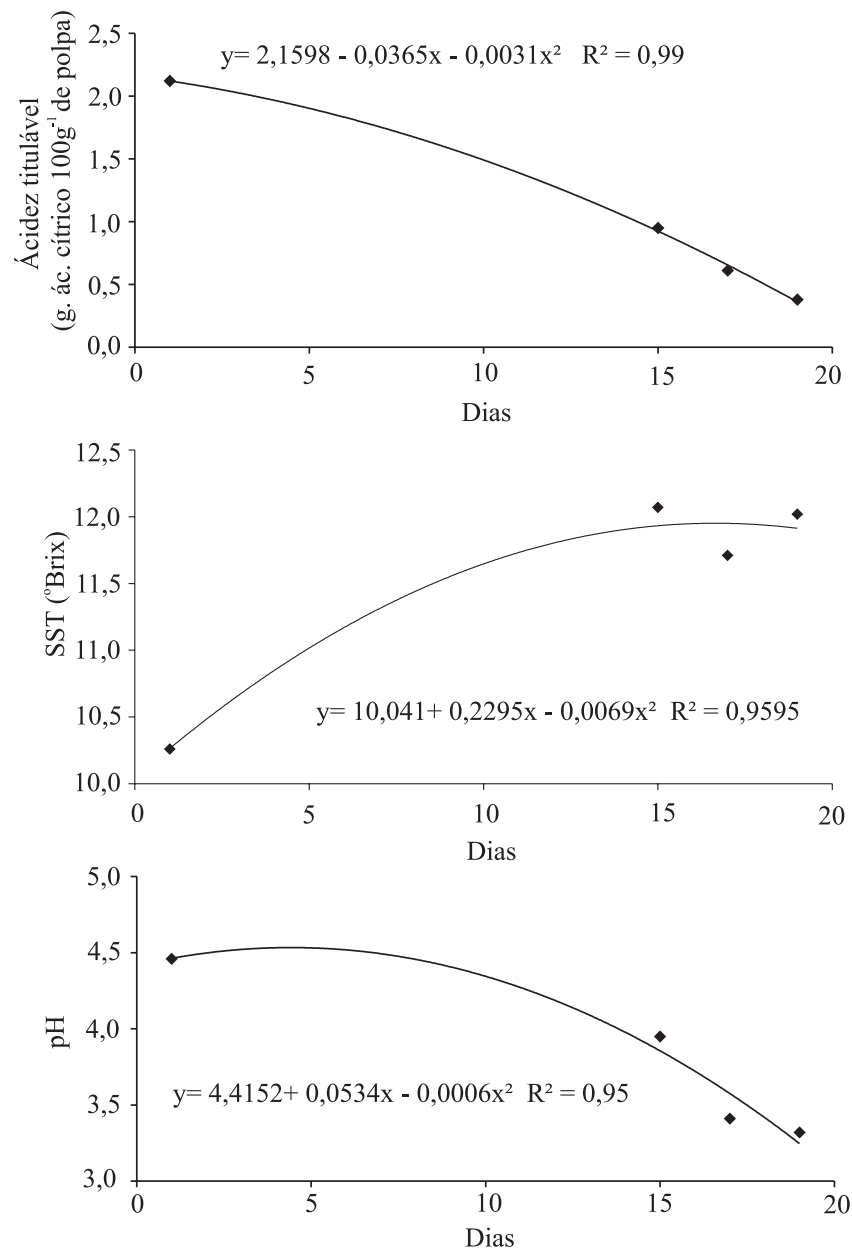

Figura 4. Ácidez Titulável (AT), sólidos solúveis totais (SST) e pH de mangas 'Tommy Atkins'. Os dados de AT foram transformados em $\mathrm{x}^{0,5}$. 
colheita (Assis, 2004). Com relação à AT, os valores apresentaram diminuição durante o amadurecimento das mangas, o que está de acordo com a redução nos teores de ácidos orgânicos após colheita, armazenamento, e o amadurecimento ocasionado pela oxidação para produção de energia no ciclo de Krebs (Lima et al., 2001). Youssef et al. (2002), em trabalho com polpa de manga congelada, encontraram resultados contrários aos observados neste trabalho, com aumento da AT após o período de armazenamento.

Quanto ao $\mathrm{pH}$, os valores encontrados na entrada da câmara fria e após 15 dias de armazenamento não demonstraram diferenças, e ficaram em torno de 3,3 e 3,4. Portanto, o armazenamento refrigerado a $13^{\circ} \mathrm{C}$ não alterou $\mathrm{o} \mathrm{pH}$ das frutas mesmo com a aplicação da radiação. Resultado semelhante foi encontrado por Antunes et al. (2003), em trabalho com armazenamento de amoras a $20^{\circ} \mathrm{C}$ e a $2^{\circ} \mathrm{C}$. Esses autores constataram que nenhuma das temperaturas proporcionou diferenças no $\mathrm{pH}$, quando comparado com as testemunhas.

\section{Conclusão}

Adose de $0,45 \mathrm{kGy}$ de raios gama pode ser recomendada como tratamento pós-colheita da manga, pois proporciona diminuição na severidade da podridão por Fusicoccum parvum, retarda o amadurecimento das frutas e não causa alteração em suas características qualitativas.

\section{Referências}

ANTUNES, L.E.C.; DUARTE FILHO, J.; SOUZA C.M. de. Conservação pós-colheita de frutos de amoreira-preta. Pesquisa Agropecuária Brasileira, v.38, p.413-419, 2003.

ARAÚJO, J.L.P. Mercado externo. 2007. Disponível em: <http:/www.agencia.cnptia.embrapa.br/Agencia22/AG01/arvore/ AG01_182_24112005115229.html>. Acesso em: 15 set. 2009.

ASSIS, J.I.S. de. Cultivo da mangueira. Petrolina: Embrapa Semi Árido, 2004. Disponível em: <http://sistemasdeproducao.cnptia. embrapa.br/FontesHTML/Manga/CultivodaMangueira/colheita. htm>. Acesso em: 25 jan. 2009.

BERNARDES-SILVA, A.P.F.; LAJOLO, F.M.; CORDENUNSI, B.R. Evolução dos teores de amido e açucares solúveis durante o desenvolvimento e amadurecimento de diferentes cultivares de manga. Ciência e Tecnologia de Alimentos, v.23, p.116-120, 2003.

CAROLE, L.; VIEITES, R.L. Conservação de pêssegos 'Biuti' por irradiação. Ciência e Tecnologia de Alimentos, v.23, p.53-57, 2003.
CARVALHO, C.R.L.; MANTOVANI, D.M.; CARVALHO, P.R.N; MORAIS, R.M. Análise química de alimentos. Campinas: ITAL, 1990. 115p.

CHITARRA, M.I.F.; CHITARRA, A.B. Pós-colheita de frutos e hortaliças: fisiologia e manuseio. 2.ed. rev. amp. Lavras: UFLA, 2005. 785p.

CIA, P.; PASCHOLATI, S.F.; BENATO, E.A.; CAMILI, E.C.; SANTOS, C.A. Effects of gamma and UV-C irradiation on the postharvest control of papaya anthracnose. Postharvest Biology and Technology, v.43, p.366-373, 2007.

FOOD AND AGRICULTURE ORGANIZATION OF THE UNITED NATIONS. FAOSTAT: agricultural statistics databases. 2009. Available at: <http://faostat.fao.org>. Accessed on: 06 Jan. 2010.

HILUEY, L.J.; GOMES, J.P.; ALMEIDA, F. de A.C.; SILVA, M.S.; ALEXANDRE, H.V. Avaliação do rendimento do fruto, cor da casca e polpa de manga tipo espada sob atmosfera modificada. Revista Brasileira de Produtos Agroindustriais, v.7, p.151-157, 2005.

LIMA, K.S.C.; GROSSI, J.L.S.; LIMA, A.L.S.; ALVES, P.F.M.P.; CONEGLIAN, R.C.C.; GODOY, R.L.O.; SABAA-SRUR, A.U.O. Efeito da irradiação ionizante $\gamma$ na qualidade pós-colheita de cenouras (Daucus carota L.) cv. Nantes. Ciência e Tecnologia de Alimentos, v.21, p.202-208, 2001.

NAGARAJA, K.V. Biochemistry of cashew (Anacardium occidentale L): a review. Journal of Food Science and Technology, v.44, p.1-9, 2007.

NEVES, L.C.; MANZIONE, R.L.; VIEITES, R.L. Radiação gama na conservação pós-colheita da nectarina (Prunus persica var. nucipersica) frigoconservada. Revista Brasileira de Fruticultura, v.24, p.676-679, 2002.

O'BEIRNE, D. Irradiation of fruits and vegetables: applications and issues. Professional Horticulture, v.3, p.12-19, 1989.

OHLWEILER, O.A. Química analítica quantitativa. 2.ed. Rio de Janeiro: Livros Técnicos e Científicos, 1980. 232p.

PFAFFENBACH, L.B.; CASTRO, J.V. de; CARVALHO, C.R.L.; ROSSETO, C.J. Efeito da atmosfera modificada e da refrigeração na conservação pós-colheita de manga espada vermelha. Revista Brasileira de Fruticultura, v.25, p.410-413, 2003.

SAS INSTITUTE. Statistical analysis system user's guide. Version 8.2. Cary: SAS Institute, 2000.

SOUSA, R.P. de; FIGUEIRAS, H.A.C.; COSTA, J.T.A.; ALVES, R.E.; OLIVEIRA, A.C. Armazenamento da ciriguela (Spondias purpurea L.) sob atmosfera modificada e refrigeração. Revista Brasileira de Fruticultura, v.22, p.334-338, 2000.

SOUSA, J.P. de; PRAÇA, E.F.; ALVES, R.E.; BEZERRA NETO, F.; DANTAS, F.F. Influência do armazenamento refrigerado em associação com atmosfera modificada por filme plástico na qualidade de mangas 'Tommy Atkins'. Revista Brasileira de Fruticultura, v.24, p.665-668, 2002.

SUBEDI, P.P.; WALSH, K.B.; OWENS, G. Prediction of mango eating quality at harvest using short-wave near infrared spectrometry. Postharvest Biology and Tecnology, v.43, p.326-334, 2007. 
THOMAS, P.; BHUSHAN, B.; JOSHI, M.R. Comparison of the effect of gamma irradiation, heat-treatment combination and sulphur dioxide generating pads on decy and quality of grapes. Journal of Food Science and Technology, v.32, p.471-481, 1985.

VIEITES, R.L. Conservação pós-colheita do tomate através do uso da radiação gama, cera e saco de polietileno, armazenados em condições de refrigeração e ambiente. 1998. 131p. Tese (Livre-Docência) - Universidade Estadual Paulista, Botucatu.

URBAIN, W.M. Food irradiation. London: Academic Press, 1986. 351p.
XAVIER, I.F.; LEITE, G.A.L.; MEDEIROS, E.V.; MORAIS, P.L.D; LIMA, L.M. Qualidade pós-colheita da manga 'Tommy Atkins' comercializadas em diferentes estabelecimentos comerciais no município de Mossoró-RN. Revista Caatinga, v.22, p.7-13, 2009.

YOUSSEF, B.M.; ASKER, A.A.; EL-SAMAHY, S.K.; SWAILAM, H.M. Combined effect of steaming gamma irradiation on the quality of mango pulp stored at refrigerated temperature. Food Research International, v.35, p.1-13, 2002.

ZULETA, S. Technical and economic feasibility of irradiating mango and other fruits. Food Irradiation Newsletter, v.2, p.25-27, 1989.

$\overline{\text { Recebido em } 23 \text { de abril de } 2010 \text { e aprovado em } 20 \text { de setembro de } 2010}$ 